\title{
Effects of Installation Methods on the Operating Environment of Outdoor Units on the Existing Platform
}

\author{
Hu Jiawei ${ }^{1, \text { a }}$, Su Shunyu ${ }^{1, b}$, Li Yuyun ${ }^{1, c}$ \\ ${ }^{1}$ School of Urban Construction, Wuhan University of Science and Technology, China \\ a445628517@qq.com, bshunyusu@qq.com, ${ }^{\mathrm{c}}$ liyu-yun@163.com
}

Keywords: outdoor unit, operating environment, installation methods, coefficient of performance

\begin{abstract}
Using the method of air enthalpy difference, an experiment on the 3HP air conditioner was conducted by changing the installation conditions. And some relevant parameters of the test system were measured by computer. The results show that, in cooling conditions, the thermal environment of the outdoor unit deteriorated when both sides of the shutter were closed, which was not conducive to the operation of the unit. If it is inevitable, we should increase the distance between the inlet and the shutter, or incline the outdoor unit properly to make the unit operate better. Besides, with the increase of the inlet temperature, the downtrend of COP changed from fast to slow in cooling conditions. However, the installation places of outdoor unit had little effect on the COP in heating conditions.
\end{abstract}

\section{Introduction}

The energy efficiency of the split air conditioner is related to the inlet air temperature of the outdoor unit. While the inlet temperature of outdoor unit is increased by $1{ }^{\circ} \mathrm{C}$, the coefficient of performance (COP) of the air conditioner is reduced by about 3\%. It will seriously affect the operation of the air conditioning units when the inlet air temperature is above $45^{\circ} \mathrm{C}$ [1]. Installation place of the outdoor units directly affects the airflow distribution in cooling conditions. The installation platforms of the outdoor units are different around buildings. Some outdoor units are installed in stainless steel bracket for its small installation platform, which increase the cost of households and affect the overall appearance of the building. Some condensing units are located in the void place of the building, which is covered by louvers. This type of installation results in poor operating environment, the air conditioner may shut down especially in extreme weather. Hence, the installation of outdoor units is investigated to guarantee the good operation effect of air conditioner.

So far many scholars in China have studied the operating environment of the outdoor unit with the experimental or CFD simulation [2-5]. Huang believes that the adverse factors of the air conditioner operation are: building construction, model selection, wind pressure, orientations, multi layer layout [2]. Cheng simulated the summer operating environment of outdoor units by FLUENT under different opening of the louver. He states that opening up the louvers is better than opening down for the operation environment of condenser units [3]. Xu studied the effects of condensation heat on the surrounding thermal environment. She recommends the outdoor unit should be installed on the leeward side wall of the leading wind. Besides, vertical multiple outdoor units should be staggered and outdoor units in same height cannot be too close [4]. Jiang studied the effect of the opening of louvers and the distance between louvers and outdoor units on operating environment in void space [5]. These studies give some reasonable suggestions for the installation of outdoor units, but they do not take into account the area of the installation platform.

In this paper, based on the simulated cooling or heating conditions in enthalpy difference lab, we changed the distance of lourves and condenser units in a fixed platform to study the effects of installation places in a fixed platform on outdoor units operating environment.

\section{Test conditions and methods}

In the laboratory of 5HP enthalpy difference laboratory, a 3HP split type air conditioning unit 
was tested. The specific parameters of the outdoor unit are shown in Table 1, and the internal and external parameters of the laboratory are shown in Table 2. The outdoor unit was placed on the test bench, and the outside was provided with a shutter. Three sides of the shutter were adjustable louvers, and the one side was a solid steel plate. There were five temperature measuring points in height of $0.3 \mathrm{~m}$ from the bench. Measuring points 1 to 3 were located in outlet. Measuring point 4 was located in the left inlet, while measuring point 5 was located in back inlet. The installation methods and the measuring points layout are shown in figure 1. The experiment was carried out by controlling the left and right sides of shutter opening and closing, and changing the relative position of the outdoor unit and the shutter with both of left and right sides of shutter closed. Experiment contents are shown in table 3.

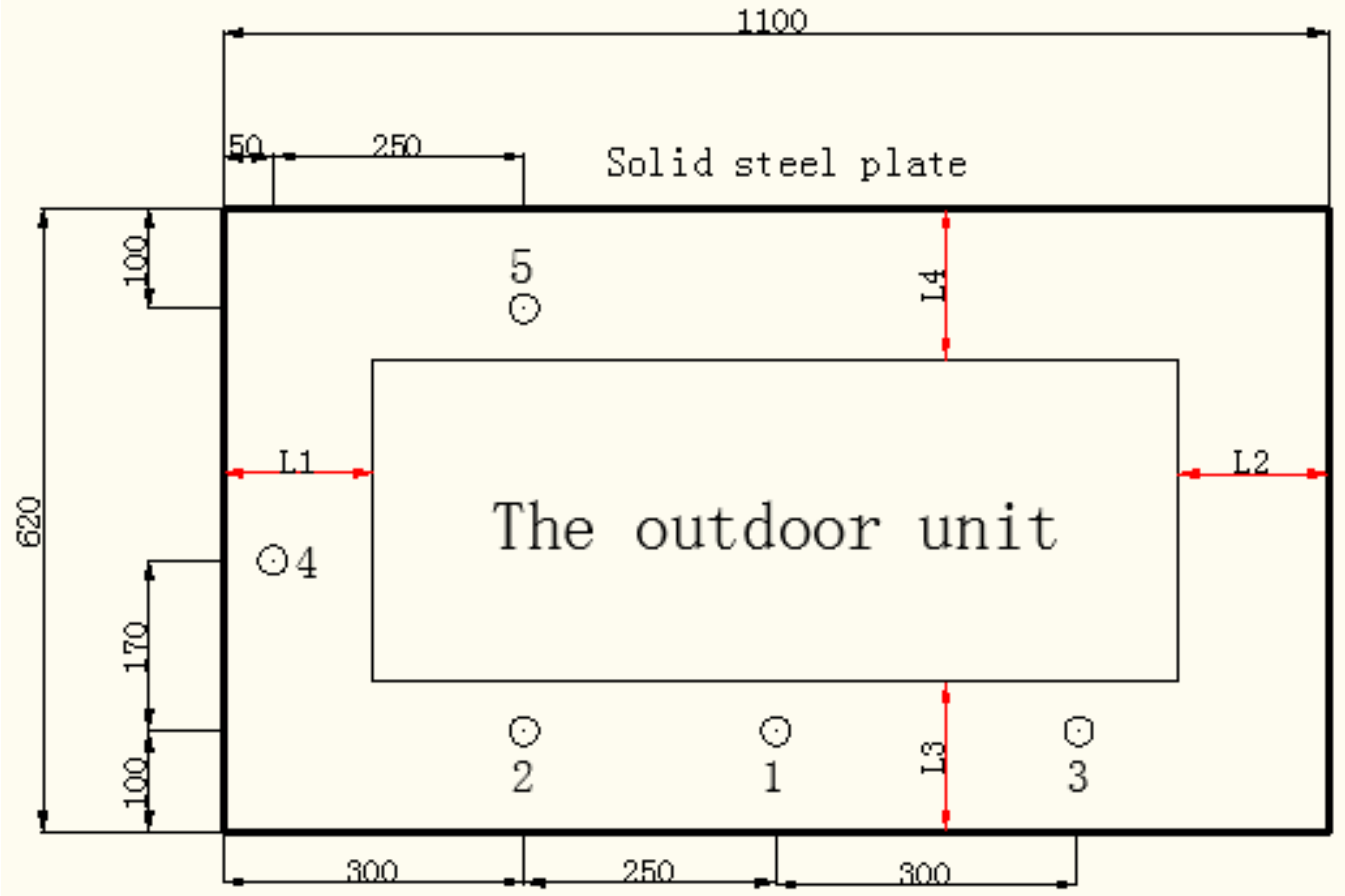

Fig. 1 Installation and the measuring points' layout

Table 1 Outdoor unit parameters

\begin{tabular}{|c|c|c|c|c|}
\hline Working conditions & Capacity $[\mathrm{W}]$ & Input power $[\mathrm{W}]$ & Size $[\mathrm{mm}]$ & Air volume $\left[\mathrm{m}^{3} / \mathrm{h}\right]$ \\
\hline Cooling & 5100 & 1520 & $800 \times 320 \times 540$ & 2800 \\
\hline Heating & 7100 & 2120 & & \\
\hline
\end{tabular}

Table 2 Internal and external parameters of the laboratory

\begin{tabular}{|c|c|c|}
\hline $\begin{array}{c}\text { Working } \\
\text { conditions }\end{array}$ & $\begin{array}{c}\text { Indoor dry bulb temperature / wet bulb } \\
\text { temperature }\left({ }^{\circ} \mathrm{C}\right)\end{array}$ & $\begin{array}{c}\text { Outdoor dry bulb temperature / wet bulb } \\
\text { temperature }\left({ }^{\circ} \mathrm{C}\right)\end{array}$ \\
\hline Summer & $27 / 19$ & $35 / 24$ \\
\hline Winter & $20 / 15$ & $7 / 6$ \\
\hline
\end{tabular}

Table 3 Experiment contents

\begin{tabular}{|c|c|c|c|c|c|c|c|c|}
\hline Number & $\begin{array}{c}\text { Working } \\
\text { conditions }\end{array}$ & $\begin{array}{c}\begin{array}{c}\text { Opening } \\
\text { degree }\end{array} \\
\end{array}$ & $\begin{array}{c}\text { Left } \\
\text { lourves }\end{array}$ & $\begin{array}{c}\text { Right } \\
\text { lourves }\end{array}$ & $\begin{array}{c}\mathrm{L} 1 \\
(\mathrm{~mm})\end{array}$ & $\begin{array}{c}\mathrm{L} 2 \\
(\mathrm{~mm})\end{array}$ & $\begin{array}{c}\mathrm{L} 3 \\
(\mathrm{~mm})\end{array}$ & $\begin{array}{c}\mathrm{L} 4 \\
(\mathrm{~mm})\end{array}$ \\
\hline 1 & \multirow{6}{*}{ Cooling } & No shutter & - & - & - & - & - & - \\
\hline 2 & & Down $30^{\circ}$ & On & On & 150 & 150 & 150 & 150 \\
\hline 3 & & Down $30^{\circ}$ & Off & Off & 150 & 150 & 150 & 150 \\
\hline 4 & & Down $30^{\circ}$ & On & Off & 150 & 150 & 150 & 150 \\
\hline 5 & & Down $30^{\circ}$ & Off & On & 150 & 150 & 150 & 150 \\
\hline 6 & & Down $30^{\circ}$ & Off & Off & 150 & 150 & 200 & 100 \\
\hline
\end{tabular}




\begin{tabular}{|c|c|c|c|c|c|c|c|c|}
\hline 7 & & Down $30^{\circ}$ & Off & Off & \multicolumn{4}{|c|}{ The outdoor unit is inclined by $8^{\circ}$} \\
\hline 8 & \multirow{4}{*}{ Heating } & No shutter & - & - & - & - & & \\
\hline 9 & & Down $30^{\circ}$ & Off & Off & \multicolumn{4}{|c|}{ The outdoor unit is inclined by $8^{\circ}$} \\
\hline 10 & & Down $30^{\circ}$ & On & On & 150 & 150 & 150 & 150 \\
\hline 11 & & Down $30^{\circ}$ & On & On & 150 & 150 & 200 & 100 \\
\hline
\end{tabular}

\section{Results and analysis}

In the process of experiment, the relevant parameters of the test system were recorded by the computer. The COP of the unit is calculated by computer. The temperatures of measure points and the COP of the unit for each group were shown in Table 4.

Table 4 Measure points' temperature and COP under different installation method

\begin{tabular}{|c|c|c|c|c|c|c|c|}
\hline Number & $\begin{array}{l}\text { Working } \\
\text { conditions }\end{array}$ & $\begin{array}{c}\text { Measure } \\
\text { point } 1 \\
{\left[{ }^{\circ} \mathrm{C}\right]}\end{array}$ & $\begin{array}{c}\text { Measure } \\
\text { point } 2 \\
{\left[{ }^{\circ} \mathrm{C}\right]}\end{array}$ & $\begin{array}{c}\text { Measure } \\
\text { point } 3 \\
{\left[{ }^{\circ} \mathrm{C}\right]}\end{array}$ & $\begin{array}{c}\text { Measure } \\
\text { point } 4 \\
{\left[{ }^{\circ} \mathrm{C}\right]}\end{array}$ & $\begin{array}{c}\text { Measure } \\
\text { point } 5 \\
{\left[{ }^{\circ} \mathrm{C}\right]}\end{array}$ & $\mathrm{COP}$ \\
\hline 1 & \multirow{7}{*}{ Cooling } & - & - & - & - & - & 3.306 \\
\hline 2 & & 47.1 & 44.1 & 39.1 & 35.7 & 37.1 & 3.163 \\
\hline 3 & & 50.2 & 50.2 & 44.1 & 41.5 & 38.4 & 2.716 \\
\hline 4 & & 47.8 & 47.0 & 41.5 & 35.5 & 36.4 & 3.046 \\
\hline 5 & & 48.3 & 47.3 & 39.0 & 42.3 & 35.7 & 2.939 \\
\hline 6 & & 50.5 & 51.0 & 43.8 & 45.0 & 38.4 & 2.617 \\
\hline 7 & & 48.6 & 48.3 & 42.3 & 38.6 & 37.1 & 2.928 \\
\hline 8 & \multirow{4}{*}{ Heating } & - & - & - & - & - & 3.416 \\
\hline 9 & & 1.0 & 0.9 & 2.8 & 5.6 & 5.4 & 3.382 \\
\hline 10 & & 2.2 & 1.7 & 2.3 & 3.4 & 4.6 & 3.372 \\
\hline 11 & & 2.4 & 2.1 & 5.1 & 6.7 & 6.5 & 3.426 \\
\hline
\end{tabular}

The influence of installation methods on the efficiency of the unit. The temperatures of measure points and the COP of the unit for each group were shown in Table 4. And the following points can be obtained from this table.

In the cooling conditions, the energy efficiency of the unit without the shutter is the highest. When the unit was covered with the shutter and both sides were opened down by $30^{\circ}$, the COP of the unit reduced by $4.34 \%$. When both sides of the shutter were closed, the energy efficiency of the unit is the lowest, and the average value of COP was 2.754. The COP of the unit with left side opened (3.046) was higher than that with right side opened (2.939). From the experiment No.3 and No.6, under the same conditions, it would reduce the COP of unit when reducing the distance between the back inlet and the wall. The shutter was made of aluminum alloy in the experiment. If it was made of cement, the effect of heat transfer would be worse, and the inlet air temperature is expected to be higher.

When the outdoor unit was inclined by $8^{\circ}$, compared to normal installation, the COP of the unit was increased from 2.716 to 2.928 . The reason for the rise of the efficiency is that inclining the unit could increase the distance of the inlet and the wall or the louvers.

In the heating conditions, the COP of the unit changed little, and the changes were within the range of $1.5 \%$ for each experimental condition. It can be concluded that the installation places of outdoor unit had little effect on the COP in heating conditions.

The influence of installation methods on thermal environment of outdoor unit. The average value of measure points 1, 2 and 3 was the average temperature of outlet air. The area weighted average value of measure points 4 and 5 was the average temperature of inlet air. Combined with 
the COP of each group, the influence of the installation methods on the thermal environment of outdoor unit was discussed in this paper. The average temperature of inlet air, the average temperature of outlet air and the COP value of each group were shown in Table 5.

When both sides of the shutter were closed(without inclining installation of the unit), the average temperature of inlet air was the highest, and it was over $40^{\circ} \mathrm{C}$. One of the reasons was that part of the air from outlet returned back to the inlet after hitting the front side of the louver, which called the "short circuit". Another reason was that the installation of both sides closed hindered the air out from the shutter flowing into the inlet. In the installation of both side closed, compared to the installation of both sides opened, the COP was reduced by $19.35 \%$. This indicated that in the installation of both sides closed, the thermal environment of the outdoor unit deteriorated, which was not conducive to the operation of the unit.

When the left side was closed, compared to the installation of right side closed, the temperature of inlet air increased by 3 degrees, and the energy efficiency was reduced by $3.23 \%$. This shows that if the installation of the outdoor unit was restricted by the platform, the priority was to increase the distance of the inlet.

When the outdoor unit was inclined by $8^{\circ}$, compared to normal installation, the average inlet air temperature of the outdoor unit was reduced from $39.3^{\circ} \mathrm{C}$ to $37.6^{\circ} \mathrm{C}$, and the COP of the unit was increased by $7.8 \%$. Thus, if permitting, inclining the unit benefited to the operation of the unit.

When the distance between back inlet and the wall was increased from $100 \mathrm{~mm}$ to $150 \mathrm{~mm}$, the average temperature of inlet air is reduced from $40.3^{\circ} \mathrm{C}$ to $39.3^{\circ} \mathrm{C}$, and the COP is increased by $3.8 \%$. It shows that increasing the distance between back inlet and the wall is beneficial to the operation of the outdoor unit.

Table 5 The average temperature of inlet air, the average temperature of outlet air and the COP value of each group

\begin{tabular}{|c|c|c|c|c|}
\hline Number & $\begin{array}{l}\text { Working } \\
\text { conditions }\end{array}$ & $\begin{array}{c}\text { Average temperature of outlet } \\
\text { air }\left({ }^{\circ} \mathrm{C}\right)\end{array}$ & $\begin{array}{c}\text { Average temperature of inlet } \\
\text { air }\left({ }^{\circ} \mathrm{C}\right)\end{array}$ & $\mathrm{COP}$ \\
\hline 1 & \multirow{7}{*}{ Cooling } & - & - & 3.306 \\
\hline 2 & & 43.4 & 36.7 & 3.163 \\
\hline 3 & & 48.2 & 39.3 & 2.716 \\
\hline 4 & & 45.4 & 36.1 & 3.046 \\
\hline 5 & & 44.9 & 37.6 & 2.939 \\
\hline 6 & & 48.4 & 40.3 & 2.617 \\
\hline 7 & & 46.4 & 37.6 & 2.928 \\
\hline 8 & \multirow{4}{*}{ Heating } & - & - & 3.416 \\
\hline 9 & & 1.6 & 5.5 & 3.382 \\
\hline 10 & & 2.1 & 4.2 & 3.372 \\
\hline 11 & & 3.2 & 6.5 & 3.426 \\
\hline
\end{tabular}

Function relation between energy efficiency and thermal environment. In the cooling conditions, the function relation between the COP and the average temperature of inlet air was shown as Figure 2.

With the increase of the average temperature of inlet air, the COP of the unit decreases. When the average temperature of inlet air increased from 36.7 to 37.6 , the COP decreased by $7.1 \%$, while the COP decreased by $3.6 \%$ when the average temperature of inlet air increased from 39.3 to 40.3 . It shows that with the increase of the inlet temperature, the downtrend of COP changed from fast to slow. It is not linear relationship between the COP and the average temperature of inlet air. 


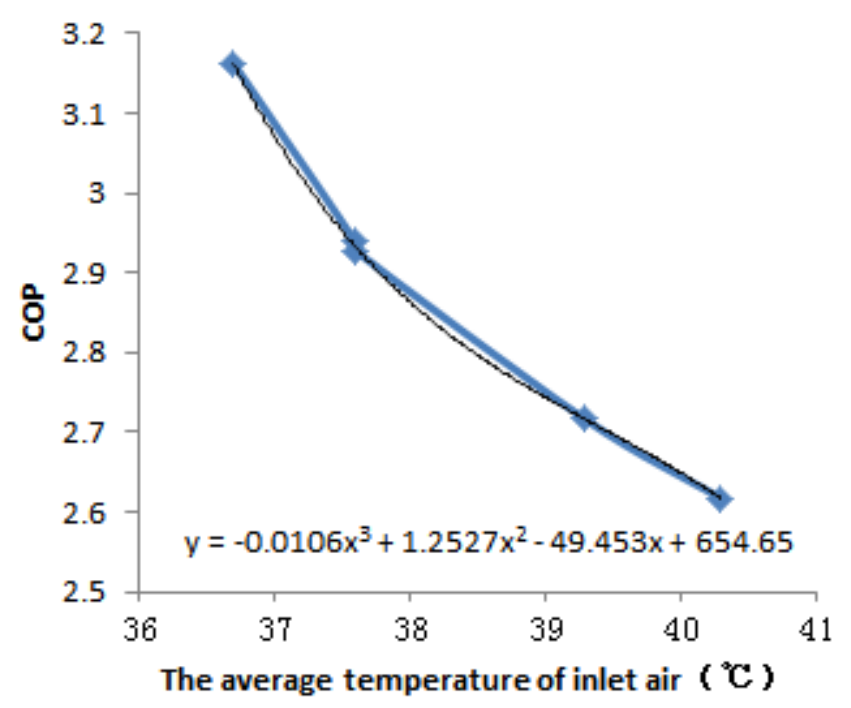

Fig. 2 The function between the $\mathrm{COP}$ and the average temperature of inlet air

\section{Conclusion}

In cooling conditions, when both sides of the shutter were closed, the thermal environment of the outdoor unit deteriorated, which was not conducive to the operation of the unit. Such situation should be avoided as far as possible. If it is inevitable, we should increase the distance between the inlet and the shutter, or incline the outdoor unit properly. It will reduce the average temperature of inlet air and improve the energy efficiency.

In cooling conditions, if only one side of the shutter can be opened, then the side near to the inlet should be opened. It will make the unit operate better.

In cooling conditions, with the increase of the inlet temperature, the downtrend of COP changed from fast to slow. It is not linear relationship between them.

The installation methods of outdoor unit had little effect on the COP in heating conditions.

\section{Acknowledgements}

The authors wish to thank the financial support of Science and Technology Planning Project of Wuhan Urban and Rural Construction Commission of China (No. Special 201501).

\section{References}

[1] T.T. Chow, Z. Lin, X.Y. Yang, Placement of condensing units of split-type air-conditioners at low-rise residences, Applied Thermal Engineering 22 (2002) 1431-1444.

[2] Z.X. Huang, Discussion on factors about location of outdoor units [J], Building Energy \& Environment, 2001, 06: 64-65. (In Chinese)

[3] Z.M. Cheng, Z. Huang, Y. Ma, Influence of pitch angle of the louver leaves on outdoor unit's operating conditions of air conditioner [J]. HVAC, Jan. 2009: 133-135. (In Chinese)

[4] C.W. Xu, G.C. Gong, Y. Bai, M.R. Chow. Effect of condensation heat release on ambient environment and natural ventilation [J], Building Energy \& Environment, 2010, 04: 9-13. (In Chinese)

[5] Y.B. Jiang, W.F. Jin, Y. Liu, W.K. Piao, Numerical simulation of thermal environment for outdoor units under different installation conditions [J], Fluid Machinery, 2013,09: 66-70. (In Chinese) 